\title{
The many challenges of interpreting recurrent moderate mitral regurgitation after MitraClip percutaneous mitral valve repair: What does it mean?
}

\author{
Vincent Chan, MD, MPH, and Marc Ruel, MD, MPH
}

\author{
From the Division of Cardiac Surgery, University of Ottawa Heart Institute, Ottawa, Ontario, Canada. \\ Disclosures: Authors have nothing to disclose with regard to commercial support. \\ Received for publication Sept 24, 2015; accepted for publication Sept 25, 2015; available ahead of print Oct 29, \\ 2015. \\ Address for reprints: Marc Ruel, MD, MPH, Division of Cardiac Surgery, University of Ottawa Heart Institute, \\ 40 Ruskin St, Suite 3402, Ottawa, ON K1Y 4W7, Canada (E-mail: mruel@ottawaheart.ca). \\ J Thorac Cardiovasc Surg 2016;151:97-8 \\ $0022-5223 / \$ 36.00$ \\ Copyright (c) 2016 by The American Association for Thoracic Surgery \\ http://dx.doi.org/10.1016/j.jtcvs.2015.09.103
}

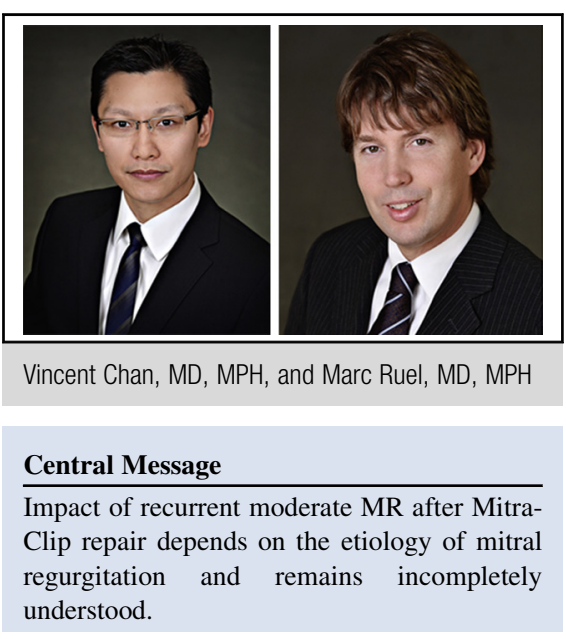

See Article page 88 .

See Editorial page 7.
The advent of percutaneous mitral valve repair with the MitraClip delivery system (Abbott Laboratories, Abbott Park, Ill) has revolutionized the treatment of severe mitral regurgitation (MR). As the application of the MitraClip continues to be refined, Buzzatti and colleagues ${ }^{1}$ present in this issue of the Journal their interesting findings that residual moderate $(2+)$ MR early after repair is associated with worse survival, symptom relief, and freedom from recurrent severe MR relative to patients with MR $1+$ or less after the MitraClip procedure.

To interpret the findings by Buzzatti and colleagues ${ }^{1}$ better and apply them to the management of our patients, however, the etiology of MR must be considered. In patients with coronary artery disease, it is well known that the presence of moderate chronic ischemic MR is associated with worse survival and more congestive heart failure relative to patients without MR. ${ }^{2,3}$ In a series of 303 patients with a previous Q-wave myocardial infarction, the presence of an effective regurgitant orifice area (EROA) greater than $20 \mathrm{~mm}^{2}$ was associated with worse total survival and cardiac survival relative to patients without $\mathrm{MR} .^{2}$ In an earlier study by the same group, the presence of MR with an EROA smaller than $20 \mathrm{~mm}^{2}$ was associated with a lower risk of congestive heart failure or cardiac death at 5 years relative to an EROA of $20 \mathrm{~mm}^{2}$ or larger (adjusted relative risk 2.97 vs 4.4). ${ }^{3}$ These data were derived from medically treated patients, however, and as yet few data are available describing the impact of residual moderate MR after valve repair.

Notwithstanding, in a detailed propensity analysis involving patients who underwent mitral repair or replacement for ischemic MR, we found that recurrent moderate MR was more common in patients after repair than after replacement. ${ }^{4}$ At a mean of 2.5 years, we found that severe MR was rare, occurring in $2 \%$ of patients undergoing repair, although recurrent moderate MR was observed in $23 \%$. Even though recurrent moderate MR was more common in patients after repair than after replacement, there was no survival difference between groups. ${ }^{4}$ The lack of a survival difference between groups in our study may relate to the similarity in late left ventricular function between patients who had recurrent moderate MR and those who did not. ${ }^{4}$ It is unclear whether a difference existed in late left ventricular function between patients with functional MR in the study of Buzzatti and colleagues. ${ }^{1}$ Perhaps differences in clinical outcome between patients with MR 2+ and MR of $1+$ or less relate to differences in ventricular function that portend mortality?

Functional MR aside, the assertion by Buzzatti and colleagues $^{1}$ that moderate MR affects outcomes in patients after repair of organic MR is also interesting. Again, few data are available describing the impact of recurrent moderate MR after repair in these patients. Extrapolating from natural history data of medically managed patients, however, moderate MR is likely associated with adverse events. In a wellreported analysis of 456 patients with asymptomatic MR, the 5-year survival of patients with an EROA smaller than $20 \mathrm{~mm}^{2}$ was $91 \% \pm 3 \%$, compared with $66 \% \pm 6 \%$ for patients with an EROA between 20 and $39 \mathrm{~mm}^{2}$. Notably, the survival of patients with an EROA between 20 and $39 \mathrm{~mm}^{2}$ was significantly lower than the expected survival of agematched patients in the US population. In that study, patients with an EROA between 20 and $39 \mathrm{~mm}^{2}$ were also found to 
have a higher cardiac mortality and more frequent cardiac events (namely death of cardiac causes, congestive heart failure, or new atrial fibrillation) than patients with an EROA smaller than $20 \mathrm{~mm}^{2}$.

Overall, one of the major hurdles of interpreting the impact of residual or recurrent moderate MR in patients after the MitraClip procedure to the complexity in the echocardiographic measurement itself. The limitations of measurement of the proximal isovelocity surface area, and thus calculation of EROA, in eccentric regurgitant jets are well known. ${ }^{6}$ It is challenging to judge the precise location of the regurgitant orifice, and because any error introduced is squared, results can be widely disparate. In addition, residual prolapse after the MitraClip procedure, as with any prolapse, may be brief, and instantaneous measures of MR with pulse wave Doppler ultrasonography may therefore be limited. ${ }^{6}$

Percutaneous options to treat MR have revolutionized the care of these patients. Nevertheless, this technology has its limitations. Although many patients benefit from this therapy, the understanding of incomplete MR reduction with this technology continues to evolve.

\section{References}

1. Buzzatti N, De Bonis M, Denti P, Barili F, Schiavi D, Di Giannuario G, et al. What is a "good" result after transcatheter mitral repair? Impact of $2+$ residual mitral regurgitation. J Thorac Cardiovasc Surg. 2016;151:88-96.

2. Grigioni F, Enriquez-Sarano M, Zehr KJ, Bailey KR, Tajik AJ. Ischemic mitral regurgitation: long-term outcome and prognostic implications with quantitative Doppler assessment. Circulation. 2001;103:1759-64.

3. Grigioni F, Detaint D, Avierinos JF, Scott C, Tajik J, Enriquez-Sarano M. Contribution of ischemic mitral regurgitation to congestive heart failure after myocardial infarction. J Am Coll Cardiol. 2005;45:260-7.

4. Chan V, Ruel M, Mesana TG. Mitral valve replacement is a viable alternative to mitral valve repair for ischemic mitral regurgitation: a case-matched study. Ann Thorac Surg. 2011;92:1358-65; discussion 1365-6.

5. Enriquez-Sarano M, Avierinos JF, Messika-Zeitoun D, Detaint D, Capps M, Nkomo V, et al. Quantitative determinants of the outcome of asymptomatic mitral regurgitation. N Engl J Med. 2005;352:875-83.

6. Zoghbi WA, Enriquez-Sarano M, Foster E, Grayburn PA, Kraft CD, Levine RA, et al; American Society of Echocardiography. Recommendations for evaluation of the severity of native valvular regurgitation with two-dimensional and Doppler echocardiography. J Am Soc Echocardiogr. 2003;16:777-802. 